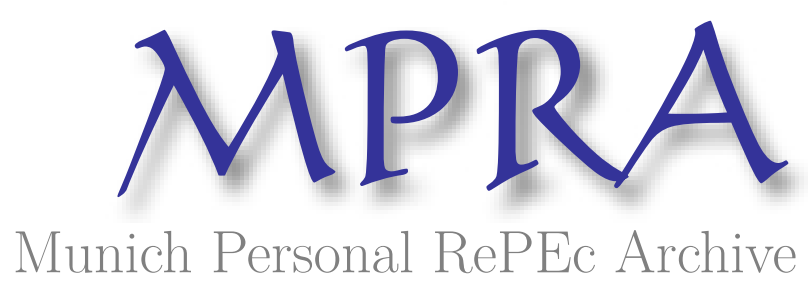

\title{
Does the Future of the Indian Public Sector Banks lie in Mergers and Acquisitions?
}

\author{
Mallick, Indrajit \\ cssscal.org
}

19 November 2004

Online at https://mpra.ub.uni-muenchen.de/32866/

MPRA Paper No. 32866, posted 17 Aug 2011 13:36 UTC 


\title{
Does the Future of the Indian Public Sector Banks lie in Mergers and Acquisitions?
}

\author{
Indrajit Mallick \\ Centre for Studies in Social Sciences, Calcutta
}

Keywords: Banks, Mergers, Efficiency

JEL CLASSIFICATION CODES: G20, G21, G22

Address for Correpondence:

Indrajit Mallick

R1 Baishnabghata Patuli Township

Calcutta 700094

Email: 1)imallick3@hotmail.com

2)indrajit@cssscal.org 


\section{Introduction}

The last twenty-five years have witnessed a spate of mergers and acquisitions (M\&A) in the banking industry in the developed countries such as USA, U.K., Germany, France, Switzerland, Netherlands, Italy, Japan etc. There were also many cross border mergers within and outside Europe. The average size of a bank has significantly gone up in these countries and giants in the banking industry have been created through this M\&A process. While the jury is still out on the long term effects of these M\&A in banking, in the short and medium run there does not appear to be a revolutionary improvement in scale and cost efficiency and only a moderate improvement in scope and profit efficiency while the gains from diversification were quite big (Berger, A. (1998), Berger,. Demsetz, and Strahan (1999)).

Despite the not so impressive record of the merged banks abroad, their ability to produce financial services seamlessly across products, geographies and clients have attracted attention in developing countries like India. In a number of recent speeches, the Finance Minister of India noted that one of the basic driving forces in Indian Banking of the future was going to be consolidation and suggested that the Indian Public Sector banks ( PSBs) should pay attention to the M\&A trends abroad and the potential in the domestic market. He also noted that Indian banks did not feature in the top 20 or 50 global banks and indicated that a major consolidation drive is required to make Indian banks world class in terms of size and quality. In this context, it should be noted that the consolidation of PSBs was first recommended by the Narasimham Committee on Financial Systems (1991) and working group was constituted by the government on bank mergers which has submitted it recommendation in October 2004.

It is not clear whether we are going to see a significant spate of mergers between Indian PSBs in the near and distant future. It is not at all clear whether such a merger wave will take place automatically without regulatory intervention, and the wisdom of regulatory intervention to induce PSBs to merge with each other can be challenged. Clearly the 
Indian context is different and unique enough to warrant a selective policy framework for bank mergers. A tendency to import trends and policies across the board would be likely to backfire. For example, in USA, the deregulation in terms of relaxation of interstate barriers to bank branching has been catalytic in the M\&A process. Further, the banking industry was based on small unit banks rather branch based banking. As a result there was significant potential for M\&As. Such conditions do not hold in Indian context where banks are based on significant branching and where there are no barriers to interstate branching. Perhaps one can justify M\&A in the Indian context given the technological revolution in banking which has been acknowledged globally to be one of the major causes of M\&A wave in banking. However, before one does so, one should pay attention to the labour intensive character of Indian PSBs. Lakshminarayanan (2005) points out that in terms of cost of funds and capital base the Indian banks are at a disadvantage. While his argument certainly has merit, one could argue that India could import cheaper capital from abroad through better banking practices and through capital convertibility. As far as increasing the size of the balance sheet is concerned, one has to clearly establish the need for it and the ability of the Indian banks to manage such a huge increase in the capital base in the short run. In Japan and Germany, banking consolidation increased the intensity of relationship between banks and firms "within" business groups and "between" groups of borrowers and banks. Risk sharing motives that have generated these mergers are not necessarily present in the Indian context. Market power can surely be increased through bank mergers as in U.K. and some European countries. However, the need for enhancing market power is not readily apparent for our banks since managerial slack or $\mathrm{x}$-inefficiency in banking typically moves directly with market power. Dymski, A. (2002) suggests that historically, most of the bank M\&As in the developing countries have taken place in terms of distressed restructuring in response to macroeconomic shocks or consolidation of undiversified small local banks prone to high risks and overexposure of portfolio in certain industries and geographies. To make a proper assessment of the need for consolidation among the Indian PSBs (as well PSB takeovers of small private banks), one has to have a clear idea about the interplay of dynamic factors in shaping the structure and performance of the banking industry. 


\section{Envisioning the Future}

The future presents both threats and opportunities for the PSBs. The banking industry structure will undergo some basic changes in respect of overall growth capability, risk management potential and competitive pressures. These changes, taken together, will imply an enhanced complexity in the banking industry structure and performance.

In the last few years the Indian GDP has been growing at a fast rate of 7-8\%. Demand for industrial and agricultural credit have accordingly grown faster than that in the 1990s and the demand for credit by the retail sector, export sector and the infrastructure sector have been growing at significantly higher rates. In the short run the Indian economy is poised to overtake many economies in terms of GDP, and there lies significant potential in small scale trade and retail credit in the semi-urban areas and in micro credit in the rural areas. In the medium and long run the Indian economy is expected to become a Global player with significant presence in World markets and lucrative rural markets. This provides an opportunity as well as a threat for the PSBs. Growth will create flexibility in asset structure, higher capital base and market share and therefore enable PSBs to generate adaptive efficiency. On the other hand, without efficient adaptation to the growth process, the PSBs cannot sustain their competitive edge and asset leverage and therefore will not be able to exploit the opportunities afforded by the domestic and the international market.

A new cohort of risk management professionals and new systems of risk management built into banking software offers tremendous advantages to all banks. The impact of these professionals and systems are bigger with respect to the PSBs in particular, in upgrading their relatively backward risk management processes. However, the new systems and people come at cost of adaptation to older systems and the costs will be highest for the PSBs for obvious reasons. A bank with a better risk management systems, process and people will be able to generate better performance than others. Such a bank can also think in terms of buying out other banks and replicating the superior risk management process on the assets bought out. 
Competition for deposits, loans and other products offered by banks will be in terms of service quality, product differentiation and interest rates. Increased competition will create finer market segments through specialization and differentiation. Across these market segments, competition will be limited due to product differentiation and specialization. Within market segments the competition in terms of quality and interest rates will accentuate the difference between the winners and losers by providing the winners with the cream customers at the retail and wholesale levels while pushing the losers to the residual market. Thus the competitive forces will provide significant gains for those banks which are able and willing to develop niche areas and improve market share in those areas. It seems probable that the winners will have an incentive to acquire the assets of the losers since they can generate greater value from those assets by combining them with the winning strategies. In those banks with farsighted management, we should expect that the hunt for assets to be already on in terms of information acquisition and processing. Also, the more the PSBs become well capitalized in the stock market, and the greater the sensitivity of the stocks to performance, the greater will be the incentive for one PSB to monitor and acquire the other PSBs.

Growth will be accompanied by increased risk which have to be managed in terms of efficient portfolio diversification, better operational risk management and innovations of risk transfer mechanisms. Competitive forces will continuously expose banks to new types of on balance sheet and off balance sheet risks. Growth, risk management enhancement and competition taken together will undoubtedly create complexity in the banking landscape by restructuring risk, return and liquidity of financial assets. Banks will be forced to choose between the following very different growth strategies:

- Focus on comparative advantage and grow on the basis of that while covering risks through off balance sheet instruments

- Focus on niche areas and be small and efficient

- Develop into an Universal Bank with several wholesale and retail services and products growing under one roof

- Carry on business as before 


\section{Optimal Strategy}

The optimal strategy will depend on the special historical conditions in the operations of each bank and the orientation towards future growth, competition and risk. For moderate sized PSBs that have succeeded in some special areas of their portfolios, the strategy that should be adopted will be that of high growth based on comparative advantages and specialization. For bigger PSBs, market power should be leveraged together with special areas of expertise to grow into a full fledged Universal Bank. For the remaining PSBs, the choice should be between that of carrying on business as before (diversified but not too big or profitable) and that of focusing on being small and efficient in niche areas.

The fundamental dilemma in the growth strategy choice is whether a PSB should try to grow organically or grow through mergers and acquisitions. Organic growth tends to be slow and is dependent on the clients and regions served by a bank, but preserves the corporate ethos and culture of a bank better. On the other hand, the consolidation with another bank may lead to expertise and synergy gains and enables the merged bank to grow faster. This creates a higher value in banking in a relatively short time. While some PSBs have unique culture and decidedly regional in nature and highly dependent on specific corporate ethos for their functioning, there are those which are national level players that can absorb other banks better in the process of growth. For the latter group, a consolidation policy is required. For the former group, organic growth is the more suitable strategy though this will imply over-exposure in terms of regions and industries. However, appropriate off balance sheet activities can counter those risks.

Mergers are strategic decisions justified by some intrinsic advantages that they confer through increased market power, economies of scale and scope and diversification benefits. Any bank would like to capture market power benefit of a merger, however the cost of acquiring a market power is potential governance problems of the bigger and more complex organization (diseconomies of scale and scope). Economies of scale gains may turn out to be quite small (as in USA and some countries in Europe) and have to be appraised well enough during the merger negotiations process. Many times, the realized economies of scale depend on the post merger restructuring of assets and rationalization 
of the work force. In the case of Indian PSBs this clearly turns out to be a difficulty. Economies of scope or "synergy" is a more distinct possibility in the sense that product A launched by a PSB in one region may be more easily distributed in another region after merger. Many times, a PSB may have overexposure to assets in one region or industry, in that case it maybe sensible to find a partner which has a portfolio of assets that varies inversely with it such that a lower risk can be achieved for the same mean rate of return. Of course, if off balance sheet asset markets like bank interest swaps are well developed, then a better hedging strategy does not necessarily require a bank merger (Mallick (2004)).

For a regulator, it is not necessarily easy to find which bank should be merged and with whom. In such a circumstance it is best to let the capital market decide. But the capital market will not function in the present environment where only a minority private investors drive the value creation process. Since all the PSBs by definition are owned by the government, there will be no effective change of ownership in mergers between PSBs. With protected ownership, there will be less internal and external monitoring of a PSB and more inefficiency (especially x-inefficiency). If PSBs tap the capital market and get privatized so that the majority of a bank's stocks are listed and traded regularly with a high volume, it will be relatively easy to pick winners, losers and "synergies" through informationally efficient asset pricing. The real challenge then would be to have antitrust authorities in banking to evaluate merger bids in terms of total value creation in terms of shareholders and other important stakeholders. For example, if merger creates significant market power then the potential beneficiary banks will have an incentive to engage in M\&A, but such mergers can increase the concentration index in the industry and lead to lower social surplus (high interest rate spread and low quality of services) created by the banking system. Such mergers should be blocked by the regulator for the sake of efficiency and equity. However, if such mergers increase the stability of the banking system by creating safer banks, or generate economies of scale and scope that enhances the efficiency of the banking industry, then the regulator should welcome them. It may be the case that the management of a PSB does not feel ready to go for M\&A despite obvious gains, under such circumstances the regulator should step in through creating the 
necessary change in management and incentive structures. However before intervening, the regulator has to clearly establish the potential gains through M\&A.

\section{Implementation}

The merger strategy can be implemented through organizational, contractual and management restructuring. For those PSBs whose optimal growth strategies are through mergers and acquisitions, the organizational challenge is that of decentralization and delegation through a multidivisional structure. As emphasized by Chandler (1962) and Milgrom and Roberts (1992), under such a structure the divisional units have to be given considerable autonomy and incentives while the Group offices and the Corporate headquarter have to take the responsibility of coordination between divisions and framing the overall policy direction. To apply this organization design principle in banking, several issues should be borne in mind. One is that some divisions or departments like the Rural Credit and Small Scale Credit Divisions are usually subsidized by other activities, and as a result there arises a moral hazard problem of under-effort and low monitoring in such units. To cope with this moral hazard problem in such units, they should be organized as profit centres with the division heads and other employees receiving a bonus for generating profits. Keeping in mind the problem of loan recovery in such priority sector lending areas, the transfer price of funds should be set lower than for other divisions or departments. The second issue has to do with the fact that some divisions or departments have overlapping zones of activity that need to be coordinated by grouping the units under a group executive. For example, the credit risk management department of a bank will need to coordinate with the statistical and planning division for appropriate data transfer and processing and will need feedbacks from the credit recovery unit regarding information about the latest pattern in recovery. The retail credit division will need better coordination with the personnel and marketing division to create financial products and services which are of high quality and that create customer satisfaction and loyalty. The grouping of divisions has to be structured to optimise with respect to such coordination issues. The third issue is that of assigning costs and benefits of transactions to the different divisional units to maximize corporate profits. The major allocation problems are with respect to the cost of funds and that of the overheads. When a division 
like merchant banking raises its own funds the problem is not so severe. However, when a division like corporate or retail credit gets the funding from resources raised at branches and cash managed at the treasury, then the issue of allocation of the cost of funds become appropriate. Units should be given incentives to economize on funds through sufficiently high transfer prices while at the same time ensuring that it does not lead to too high lending rates that will cause adverse selection and moral hazard. With Basel II, operational risks have entered into the formal category of risks and provisioning, management and control of such risks have accordingly become important.

\section{Conclusion}

Indian PSBs have long been burdened with the responsibility of development banking through mobilizing deposits at the countryside and providing finance to agriculture and small scale industries at subsidized rates. It is time to marry the social responsibility of these banks with proper commercial orientation so that they can survive and prosper in an environment of high growth, competition and risks. For some PSBs today, this implies the need for mergers. For a bank that has the capacity to grow in terms of its intrinsic comparative advantage but is constrained due to the problems of inter-regional penetration, merger with a similar bank (in terms of comparative advantage and portfolio) will provide an avenue to grow optimally. Similarly, a bank of the size and experience of SBI can aspire to become a universal bank by acquiring smaller banks with lucrative retail and wholesale portfolio and through strategic alliances with investment banks, insurance companies and asset management firms. For others, there are other strategic configurations that are optimal. Given the current distribution of assets and portfolio performance of the PSBs, most of them belong to the residual category.

The process of M\&A will be socially beneficial and value adding if PSBs are privatised before placing merger bids. Since bank privatisation is not immediately on the anvil, one may have to resort to relatively more distortionary means like partial privatisation and restructuring the incentives of the bank management. 


\section{Bibliography}

Berger, A. (1998). "The Efficiency Effects of Bank Mergers and Acquisition: A Preliminary Look at the 1990s Data." in Bank Mergers \& Acquisitions, edited by Y. Amihud and G. miller. Boston, MA. Kluwer Academic: 79-111.

Berger.A, R. S. Demsetz, and P.E.Strahan (1999). "The Consolidation of the Financial Services Industry: Causes, Consequences and Implications for the Future”, Journal of Banking and Finance, 23, 135-90

Chandler, Jr A. D, (1962). Strategy and Structure. (Cambridge, MA, MIT Press)

Dymski, A. (2002). "The Global Bank Merger Wave: Implications for Developing Countries". The Developing Economies XL-4: 435-66.

Lakshminarayanan, P. (2005) "Consolidation in the Banking Industry through mergers and Acquisitions", IBA Bulletin, 92-99

Mallick, I. (2004). "Comparative Advantage in Banking and Strategic Specialization in Cournot Games", in Trade, Finance and Development, edited by B.Chatterjee and A.Raychaudhuri. DEEP \& DEEP Publications Pvt. Limited.

P. Milgrom and J. Roberts (1992). Economics, Organization and Management. (Prentice Hall, Englewood Cliffs, New Jersey 07632) 